Journal of Computer Science 1 (4): 500-504, 2005

ISSN 1549-3636

(C) 2005 Science Publications

\title{
e-Learning Based on Context Oriented Semantic Web
}

\author{
${ }^{1}$ Muna, S. Hatem, ${ }^{2}$ Haider, A. Ramadan and ${ }^{3}$ Daniel, C. Neagu \\ ${ }^{1,2}$ College of Science, Department of Computer Science, Sultan Qaboos University \\ P.O. Box 36, Al-Khod 123, Muscat, Oman \\ ${ }^{3,1}$ School of Informatics Department of Computing, University of Bradford \\ Richmond Road, Bradford, West Yorkshire, BD7 1DP, UK
}

\begin{abstract}
The Semantic Web has opened new horizons for internet applications in general and for eLearning in particular. The e-Learning community is aiming at having much more effective services than what is currently provided by any of the available computer aided tutoring, or learning management systems. The e-Learning process is no more restricted to providing courses online. Nowadays, knowledge is distributed throughout the Web on millions of pages, PDF files, multimedia and other resources. The learner is not necessarily someone who is registered in a course or needs eLearning to support a particular course. Students and researchers need vast amount of material and spend considerable amount of time trying to learn about a particular subject or find relevant information. This research reports on the work in progress to develop a framework for Semantic Web mining and exploration, a practical method towards Semantic Web application to e-Learning along with its design framework is suggested.
\end{abstract}

Key words: Adaptive environment, e-Learning, ontology, RDF repository, semantic web

\section{INTRODUCTION}

It used to be enough for colleges and universities to post course schedules and syllabi online, but things have changed with the introduction of the Learning Management Systems (LMS) ${ }^{[1]}$, Web-based course tools like WebCT ${ }^{[2]}$ and BlackBoard ${ }^{[3,4]}$, Virtual Laboratory $^{[5]}$ and the Live Meeting software ${ }^{[6]}$.

Web-based educational systems are becoming very popular and are being used by many educational institutions. The International Data Corporation (IDC) predicted in its January 2005 report that e-Learning will have $\$ 21$ billion market in 2008 , while was only $\$ 6.5$ billion just two years ago ${ }^{[7]}$.

In practice, the available tools are not considered effective; at Sultan Qaboos University we proposed some enhancement to WebCT to extend its services ${ }^{[8]}$. However, a truly effective e-Learning solution must be provided to meet the growing demands for e-Learning by students, employee, researches and lifelong learners. Efficient management to the available information on the Web can lead to an e-Learning environment that provides learners with interaction with the most relevant material.

The concept of Semantic Web ${ }^{[9]}$ is adding powerful features to the Web. The focus of internet research is targeted towards creating a global decentralized knowledge based system; hence the term Semantic Web is introduced as: "a vision for a next-generation network that lets content publishers provide notations designed to express a crude meaning of the page instead of merely dumping arbitrary text onto a page. Autonomous agent software can then use this information to organize and filter data to meet the user's needs" ${ }^{,[10]}$. Current research in the Semantic Web area should eventually enable Web users to have an intelligent access to Web services and resources. The eLearning will particularly benefit from the Semantic Web.

The semantic web main concepts and tools: The concept of ontology is becoming the basic framework for Semantic Web. Ontologies provide a vocabulary of terms whose meaning (Semantics) are formally specified. Ontology is popular because it provides a shared and common understanding of a domain that can be communicated between people and application systems $^{[11]}$.

Software developers are increasingly creating tools for adding machine-processable-information to the Web Pages. They aim at providing unambiguous meaning to the Web content that can be processed by software agents. Standards and tools for the Semantic Web are under development of the World Wide Web Consortium (W3C). W3C describes the aim of its activities for Semantic Web as: "to develop enabling standards and technologies designed to help machines understand more information on the Web so that they can support richer discovery, data integration, navigation and automation of tasks." Based on this

Corresponding Author: Muna, S. Hatem, College of Science, Department of Computer Science, Sultan Qaboos University, P.O. Box 36, Al-Khod 123,Muscat, Oman 
approach, more accurate results of information search techniques will be proposed. Moreover, the information integration, as obtained from various sources, is addressed in a homogeneous way and algorithms for data fusion in data warehouses required by applications from digital libraries to e-business and e-health services are treated accordingly.

Semantic Web requires languages such as the eXtensible Markup Language (XML) and the Resource Description Framework (RDF) for adding structure and meaning, along with relationships between Web information sources ${ }^{[12,13]}$. The development of languages like Web Ontology Language (OWL) has provided a standard for ontology preparation ${ }^{[14]}$. The eXtensible Stylesheet Language (XSL) ${ }^{[15]}$, the SiRPAC parser $^{[16]}$, the ontology editor Protégé $e^{[9]}$, Sesame ${ }^{[9]}$, the RDF repository and query service, the ontology server Ontobroker and the Ontology Editor (OntoEdit) ${ }^{[17]}$ have been developed and are currently used by different communities working for Semantic Web applications.

The commercial Ontology Support Tool SNOBASE is an ontology management environment developed by IBM Alphaworks ${ }^{[14]}$. It provides a mechanism for querying ontologies and a programming interface for interacting with ontologies, written in RDF Schema and OWL. The AKT Portal at the University of Southampton is largely based on ontologies and uses $\mathrm{OWL}^{[14]}$. The CS AKTive space application is an explorer for investigating the computer science research domain in the United Kingdom ${ }^{[18]}$.

However, the Semantic Web is still mostly a vision. Applications of Semantic Web concepts have not yet been totally put into practice. Semantic Web applications like $\mathrm{SECO}^{[19]}$ acts as a mediator that aggregates arbitrary RDF files from the Web and constructs a user interface in HTML from the integrated data set it builds. SECO presents some of the important Semantic Web concepts and future work needed. KAON (Karlsrude Ontology) is one of the most promising works towards Semantic Web implementation $^{[17]}$; it is an initiative aimed at providing a common framework for Semantic Web. SEAL (Semantic portAL) is a framework for managing community Web sites and Web portals based on ontology ${ }^{[20]}$. AKT is a multi-million pound six-year project that aims at creating knowledge management system and uses the Semantic Web to extract the value from the available informational assets ${ }^{[21]}$.

Recently, Microsoft announced its new search engine (beta) ${ }^{[22]}$, Google has produced an academic version of its search engine (scholar) ${ }^{[23]}$. Both these engines have added some sort of intelligence to the Web search. We see these two products are an attempt to fulfill some of promises of the Semantic Web. Obviously, we are at the beginning of a long road that lies ahead. Further steps are needed to develop new approaches and to transfer the new and current available approaches into practice ${ }^{[24]}$.
Adaptive Environments for e-Learning is one of the several trends in Semantic Web researches. Adaptive Environments greatly help the learner through learning resources that are directed towards the learner's goals and abilities which are automatically discovered according to his previous navigation patterns and performance.

e-Learning research and tools: The success of the Web information accessing has encouraged researchers in the field of Intelligent Tutoring systems (ITS) and LMS to focus on issues of interoperability and reuse ${ }^{[25]}$. There are many attempts at building learning platforms and tools:

* Brokerages for educational systems: They are systems that have their own educational metadata schemes. A brokerage aims at providing not only searching services for learners, it aims to include resource acquisition, distribution and billing, in addition to easy access to content providers. System like ARIADNE, GEM and EdNA provide a front end to catalogue learning objects together with a Web-based searching environment. Other systems like GESTALT can be considered as a draft proposal for a domain CORBA Facility for educational brokerage (CORBAlearn) ${ }^{[26]}$.

* Commercial Web-based course tools: e-Learning portals such as WebCT and BlackBoard.

* Sharable Courseware Object Reference Model (SCORM) by Advanced Distributed Learning (ADL): This is a good example of the effort directed to build a suite of technical standards that enable Web-based learning systems to find, import, share, reuse and export learning content in a standardized way.

* The Open Knowledge Initiative (OKI): the Massachusetts Institute of Technology (MIT) project initiated in order to provide all of their courses online.

* Conzilla: a first prototype of a concept browser that has two modes of exploration, Browsing and Querying $^{[25]}$.

* Edutella: is an open source project that is an RDFbased e-Learning $\mathrm{P} 2 \mathrm{P}$ network aimed to accommodate heterogeneous learning resource metadata repositories in a P2P manner and facilitate the exchange of metadata between these repositories based on RDF. Edutella set of services include searching, mapping and replication ${ }^{[25,27] \text {. }}$

* Virtual Workspace Environment (VWE): It is a distributed Learning Management System. This is a small configurable operating system that can run in a Web browser, which allows users to access their own learning environment from everywhere ${ }^{[28]}$.

* Personalized Access to Distributed Learning Repositories (PADLR): The vision of the project is the distributed Learning Web Infrastructure, which 
"makes it possible to exchange /author /annotate/ organize/ market and personalize /navigate/ use/ reuse modular learning objects, supporting a variety of courses, disciplines and universities"[29].

* The courseware watchdog project: The research produced the Basic Support for Cooperative Work (BSCW). It is intellectual property owned by FIT and OrbiTeam. BSCW is a tool for computer supported collaboration, projects can be managed online and access to important documents from anywhere, at anytime. It is suited for small and medium enterprises. BSCW is more suitable for eBusiness than e-Learning ${ }^{[30]}$.

* Internet2 Project of US universities: The Internet2 Middleware Initiative (I2-MI) is working toward the deployment of core middleware services at Internet2 universities. It aims at making advanced network applications much easier to use. One of the most promising initiatives of the Internet 2 project is the Internet 2 Commons.

In addition, standardization in the e-Learning domain is one of the important active and evolving processes. The standardization process is not an easy task; it is expected to last for many years to come. Among the main contributors to standardization effort are the IEEE's Learning Technology Standardization Committee (LTSC), the IMS Global Learning Consortium, the Aviation Industry CBT Committee (AICC), the US Department of Defense's Advanced Distributed Learning (ADL) initiative and projects Alliance of Remote Instructional Authoring and Distribution Networks for Europe (ARIADNE) ${ }^{[26]}$.

In short, all of the above projects, concepts and tools aim at finding a practical, efficient and attainable approach to teaching and learning. The commercially available tools are not effective yet and there has not been any particular tool that reflects a ready made standard.

Sultan Qaboos University e-Learning web services: The e-Learning services at SQU are provided through each of the following services:

* Currently SQU uses WebCT to provide the e-Learning services for most of the courses offered to its students. There are many limitations in this available service; the main limitations are pointed as follows:

* A course that is published on WebCT requires design preparation, the instructor has to prepare the course, enter student list and enter course material. The privilege of accessing a particular course is assigned by the WebCT administrator for the instructor and by the instructor for the students.
* When a different instructor teaches the same course, the material is prepared again by the new instructor.

* Not many instructors are using WebCT full tools; some are using very limited features.

* Although more than 30 different universities in the Middle East region are using WebCT, there is no actual sharing of the material that is available.

* The student can not benefit from any extra course or information, even if this information is available on WebCT, simply because the student does not know about the existence of that particular information.

* Very limited tools can be added to WebCT. If a particular student, for example, needs to compile his $\mathrm{C}++$ program, he can not do so without having the compiler on his local machine.

* No utilization for the Synchronous teaching offered by WebCT.

* The Digital Video Library that contain many educational material that can currently be viewed online.

Vision of Sultan Qaboos University semantic web and e-Learning services

General framework: SQU Web e-Learning services can be enhanced if the Semantic Web services are introduced. In a separate research paper ${ }^{[24]}$ we suggested a context oriented Semantic Web architecture for SQU Web services. The proposed architecture is shown in Fig. 1. The implementation of this structure is a multi step process comprising the following:

* SQU Ontology Creation: The knowledge engineer creates and maintains SQU ontology. An ontology editor (like OntoEdit, Protégé or OI-modeler ${ }^{[9]}$ ) is used for creating the initial ontology. The Knowledge Engineer updates the ontology at a later stage using the appropriate ontology editor. The Ontology learner captures new concepts and updates the ontology accordingly.

* RDF repository: the integrated RDF repository is to be constructed. It includes RDF triples of every Web page that can be provided by any of the subsequent services. The context and content parser will be used to generate the RDF repository. The Web services engine captures new RDF and updates the RDF repository. Off-line updates on any of the databases involved can be imported and processed by the context and contents parser on a regular basis.

* SQU Web Resources: This is the warehouse that contains all the Web page templates and the multimedia resources needed by the Web page generator. This warehouse is created by the context and content parser and updated by Web developer. 
* Users Profiles: The central service staff generates the user profiles database file. The central service staff uses special forms to update this profile via the Web. The ontology learner automatically updates the users' profiles depending on the user previous navigation history.

* The Web Services Interface: It represents the Semantic Web portal. The dynamic Web generator displays portal page for each user. SQU Web users access their pages via the Common User Interface.

* Software Agents: Access to SQU RDF repository and Web resources can be permitted to software agents; they use query language, such as the objectoriented RDF Query Language (RQL) ${ }^{[31]}$, to provide the functionality of querying the RDF instances in the repository and SQU ontology.

* Common User Interface: SQU Web users access their pages via the common user interface. The various users of the Website are required to enter their username and password. The users profiles database is checked for authorized access. The relevant access right is granted by the Web service engine. The Web service interface displays the suitable user interface for each user depending on the decision made by the Web service engine.

e-Learning service: The e-Learning services can be provided for different type of users as follows (Fig. 2):

* Registered students in the university: depending on the user profiles, the Web service engine decides on the adaptive portal and interface for that particular student. For example, normal undergraduate students will access mainly links to the university resources (including WebCT), links to additional material related to the currently registered subjects or projects. New systems can also be plugged in. A system like PEARL ${ }^{[32]}$ can help disabled students to do live experiments in the virtual laboratory. The Web portal display for disabled students might offer certain experiments or links.

* Academic and research staff will mainly benefit from the fact that the system will save their search trends, depending on the profile, subjects of interest and the subject allocated. Appropriate links are displayed on their pages. In addition, the personal home page on the Web that will dynamically be constructed by the Semantic Web will keep links to description, WebCT material, registration lists, books in the library or material in the digital library that is related to the course the academic staff is teaching.

* Anonymous users and software agents can benefit from finding related results for their queries, such as a recommended course material, or multimedia files in the digital library.

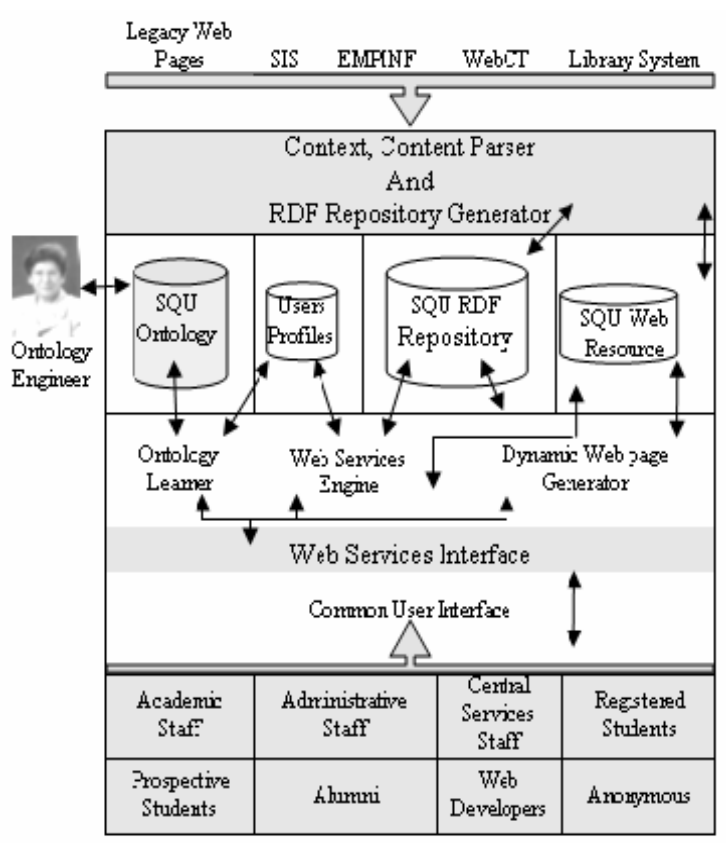

Fig. 1: The conceptual architecture of SQU semantic web service

SQUSW Server

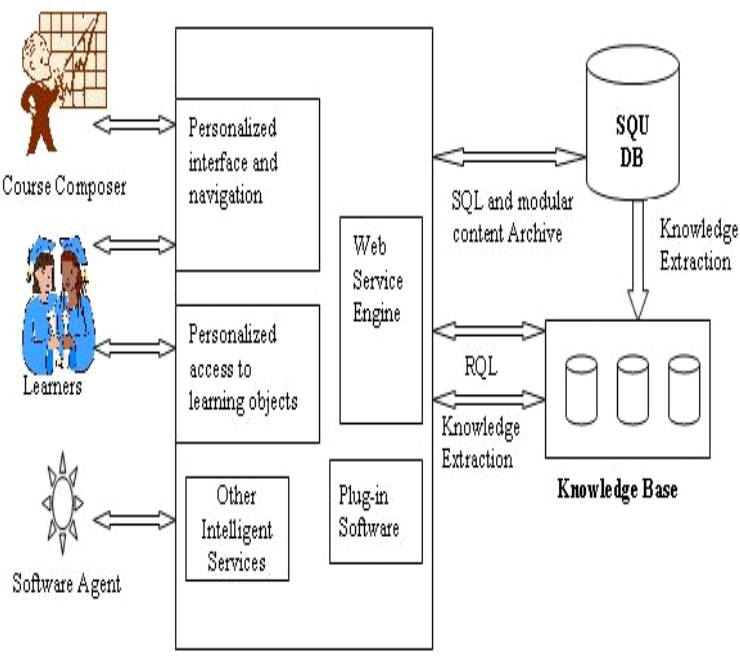

Fig. 2: Overview of the data flow in the proposed e-Learning system

* The university and the community can benefit by querying the Semantic Web about experts in particular subjects, or people working on particular topics.

\section{CONCLUSION AND FUTURE WORK}

This proposed approach will ensure that SQU develops an RDF repository reflecting the actual data and the Semantics of all of its resources including courses on WebCT and materials of the Visual Library. 
It will enable SQU Web developer to also annotate Arabic materials. Courses that require special privileges to be accessed can be handled according to the user profiles and privileges users have. The proposal will not actually cancel the role of the current WebCT system or Visual Video system; in fact it will empower the functionality of these two systems by presenting them to many users that do not even know of their existence. In addition to that, any material available at SQU Website or any of the computing services will be easily accessed by learners according to their privileges. One important advantage to using the Semantic Web concept with e-Learning is that the university can advertise the courses they have, especially those offered by the Center for Community Service and Continuing Education, to learners interested in such services. eLearning and E-Business activities via the Semantic Web are expected to be an efficient activity.

\section{REFERENCES}

1. http://www.isopia.com/ILMS/ILMS.html

2. Murray W. Goldberg and Sasan Salari, 1997. An update on WebCT (World-Wide-Web CourseTools) A Tool for the creation of sophisticated web-based learning environments. Proc. NAUWeb, June 12-15, Flagstaff, Arizona.

3. Blackboard Inc., Blackboard Learning System, 2004. http://www.blackboard.com/highered/academic/ls/index. $\mathrm{htm}$

4. Blackboard Inc., Educational Benefits of Online Learning, 2000. http://www.blackboard.com

5. http://www.infoworld.com/articles/eu/xml/00/07/24/ 000724 eutrain.html

6. http://www.microsoft.com/office/livemeeting/prodinfo/ overview.mspx

7. http://www.internet2.edu/initiatives/

8. Al-Khanjari, Z.A., N.S. Kutti and M. Hatem, 2006. An extended e-Learning architecture: integrating software tool within the e-Learning portal. The Intl. Arab J. Inform. Technol. (IAJIT), to be published in vol. 3, no. 2, April 2006.

9. Ying Ding, Dieter Fensel, Michel Klein and Borys Omelayenko, 2002. The Semantic Web yet another hip. Science Direct-Data \& Knowledge Engineering.
10. Ogbu, U., 2002. The language of the semantic web. New Architect.

11. Davies, J., D. Fensel and F. Harmelen, 2002. Towards The Semantic Web. Willy.

12. http://www.w3schools.com/xml/default.asp

13. http://www.w3schools.com/rdf/default.asp

14. http://www.w3.org/2004/OWL

15. Deitel, H.M., P.J. Deitel, T.R. Nieto, 2002. Internet \& World Wide Web How To Program. Prentice Hall.

16. http://www.w3.org/RDF/Implementatios/SiRPAC/

17. http://ontobroker.aifb.uni-karlsruhe.de/index_ob.html

18. http://www-agki.tzi.de/swc/csaktivespace.html

19. Harth, A., 2004. An integration site for semantic web metadata. Science Direct.

20. Maedche, A., S. Staab, R. Studer, Y. Sure and R. Volz. SEAL- tying up information integration and web site management by ontologies. IEEE Data Eng. Bull., 25: 10-17.

21. http://www.aktors.org/akt/

22. http://beta.search.msn.com

23. http://scholar.google.com

24. Hatem, M., D. Neagu and H. Ramadan, 2005. Context oriented rdf repository for semantic web: Application to Sultan Qaboos University Web Services. Proc. 6th Informatics Workshop 2005, Bradford University, UK.

25. Ambjörn Naeve, Mikael Nilsson and Matthias Palmér, 2001. e-Learning in the semantic age. KTH, Stocholm University.

26. Anido, L., J. Rodríguez, M. Caeiro and J.M. Santos, 2003. High-level brokerage services for the e-Learning domain. Computer Standards and Interfaces, 25: 303-327.

27. http://ifets.ieee.org/periodical/7_2/8.pdf

28. http://iet.open.ac.uk/pearl/

29. Personalized Access to Distributed Learning Repositories (PADLR), Research Groups 2001.

30. Staab, S. and R. Studer, 2001. Courseware Watchdog. Univ. Karlsruhe and Institute (AIFB).

31. http://www.openrdf.org/doc/rql-tutorial.html

32. http://www.fastuk.org/project_details.php?Ref=481 